\title{
ATUAÇÃO DOCENTE NA INTER-RELAÇÃO DOS LETRAMENTOS ALFABÉTICO E DIGITAL NO CIBERESPAÇO
}

\author{
M. F. L. CHAGAS ${ }^{1 *}$, K. R. A. DEMOLY ${ }^{2}$, J. V. REBOUÇAS ${ }^{1}$ e K. V. GONÇALVES ${ }^{2}$ \\ ${ }^{1}$ Universidade do Estado do Rio Grande do Norte - UERN \\ ${ }^{2}$ Universidade Federal Rural do Semi-Árido - UFERSA \\ fatima.aee@gmail.com*
}

Artigo submetido em junho/2012 e aceito em dezembro/2014

DOI: $10.15628 /$ holos.2014.963

\section{RESUMO}

A pesquisa intervenção aqui apresentada objetivou diminuir o distanciamento entre professores e tecnologias da informação e da comunicação, interagindo com gêneros textuais no ciberespaço. Utilizou uma metodologia que envolveu entrevistas com os professores, oficinas pedagógicas em um curso de formação continuada. Dessa forma observaram-se resultados apresentados nas escritas dos professores, como mudanças nos modos de compreensão acerca do computador e outras ferramentas digitais no fazer pedagógico apropriando-se de gêneros textuais que envolvem os letramentos alfabético e digital.
Atualmente os gêneros textuais digitais são bastante utilizados na formação inicial e continuada de educadores pela necessidade da inclusão digital de professores com atividades no ciberespaço. A fundamentação teórica que norteou este trabalho parte da perspectiva sociointeracionista e histórica da linguagem, defendida por Bakhtin/Voloshinov (1992/ 2003/2006); Xavier (2002) e Pierre Lévy (1996/1999) que permitiram compreender os processos cognitivos e subjetivos potencializados no operar dos sujeitos com diferentes gêneros textuais no ciberespaço.

PALAVRAS-CHAVE: letramento digital; tecnologia; aprendizagem

\section{TEACHING PRACTICE IN INTER-RELATIONSHIP OF LITERACIES ALPHABETIC AND DIGITAL IN CYBERSPACE}

\begin{abstract}
The intervention research presented here aimed to reduce the distance between teachers and information technologies and communication, interacting with genres in cyberspace. Used a methodology that involved interviews with teachers, teaching workshops in a continuing education course. Thus observed results presented in the writings of teachers, such as changes in ways of understanding the computer and other digital tools in the pedagogical appropriating genres involving alphabetic and digital literacies. Currently the digital
\end{abstract}

genres are widely used in initial and continuing educators need the digital inclusion of teachers with activities in cyberspace. The theoretical framework that guided this work comes from the historical and social interactionist perspective of language advocated by Bakhtin / Voloshinov (1992/2003/2006) Xavier (2002) and Pierre Lévy (1996/1999) that allowed us to understand the cognitive processes and subjective potentiated operate in the subjects with different genres in cyberspace.

KEYWORDS: Literacy digital, Technology, Learning. 


\section{INTRODUÇÃO}

A aprendizagem no espaço escolar, desde o início da escolarização, busca dar enfoque ao desenvolvimento da língua materna, suas evoluções e utilizações para compreender, analisar e enfrentar situações cotidianas diversas. Essa linguagem é estudada através de diferentes portadores e gêneros textuais, inclusive os digitais.

Com a evolução tecnológica, é evidente a necessidade de a Escola aprofundar novos estudos e proporcionar oportunidades de promover um encontro real entre professores e tecnologias, a fim de propiciar melhores resultados nas construções cognitivas, inserindo-os, assim, no contexto digital. Tendo em vista que atualmente o docente convive com alunos "nativos da informática", nascidos na era digital, que acessam com facilidade informações através da televisão, internet, telefone, livros, além das vivências do seu cotidiano que constitui uma fonte inesgotável de conhecimento, torna-se impraticável a técnica de transmissão de conhecimento de forma unilateral, somente pela tradição. Dessa forma, os recursos da informática favorecem a autonomia e independência tanto do educador como do aluno.

Pensando em um trabalho educativo em ciberespaço, é relevante destacar a importância de textos eletrônicos e hipertextos no letramento alfabético e digital, suas reais contribuições no processo de ensino e aprendizagem de leitura e escrita. Nessa perspectiva, a escola deve (re)conhecer a riqueza dessas práticas de leitura e escrita, como por exemplo os e-mails e a escrita em redes sociais como possibilidades de letramento, de modo que o docente possa direcionar essas possibilidades de aprendizagens, sendo necessário o envolvimento de alunos e professores nessas novas formas de ler e escrever, como práticas de letramento advindas da internet, tendo em vista que essas novas interações possibilitam um avanço da linguagem dialógica, tão importante na formação de cidadãos nesta sociedade que vive em constante contato com tecnologias da informação e da comunicação.

Para compreender na prática as possibilidades da inter-relação dos letramentos alfabético e digital no ciberespaço, organizamos em uma escola pública um curso de formação para professores do Ensino Médio envolvendo diversos gêneros textuais com atividades para serem desenvolvidas em sala de aula e no laboratório de informática. Utilizou-se uma metodologia qualitativa que envolveu entrevistas com os professores, oficinas pedagógicas em um curso de formação continuada.

A fundamentação teórica que norteou esta experiência parte da perspectiva sociointeracionista e histórica da linguagem, defendida por Bakhtin/Voloshinov (1992/ 2003/2006); Marcuschi e Xavier (2004) e Pierre Lévy (1996/1999) possibilitando compreender os processos cognitivos e subjetivos potencializados no operar dos sujeitos com diferentes gêneros textuais no ciberespaço.

Neste estudo, evidencia-se que o letramento é uma vertente de pesquisa que tem suscitado um grande interesse entre os pesquisadores. Com isso, apoia-se na necessidade de se analisar uma situação discursiva que envolve leitura e escrita como prática sociointeracionista da linguagem. Pelo fato de ser feito a partir dos gêneros textuais, considera-se que esse tema apresenta uma estreita relação entre o processo de letramento e as diferentes formas discursivas existentes no espaço social, em especial na internet, que representa ambiente para interação dos 
internautas através da linguagem verbal, imagens, sons, entre outros elementos hipertextuais relativos ao letramento.

\section{GÊNEROS TEXTUAIS DIGITAIS E INTERAÇÕES NO CIBERESPAÇO}

$\mathrm{Na}$ atual sociedade, com tantos avanços tecnológicos, a construção do letramento digital se apresenta como uma necessidade educacional e de sobrevivência social, tendo em vista a demanda de atuação reflexiva na sociedade. Lévy (1999) considera a internet como uma coordenação das inteligências em tempo real, que atinge uma mobilização efetiva nas ações, através das quais os sujeitos deixam de ser isolados para serem atuantes e transformadores em uma rede de comunicação, por meio das ferramentas computacionais, lidando ao mesmo tempo com muitas pessoas, sem limitações de tempo e espaço físico.

Bakhtin nos esclarece sobre a construção da língua, expondo situações que vão além da estrutura fechada presente em livros e gramáticas.
A língua materna - sua composição vocabular e sua estrutura gramatical - não chega ao nosso conhecimento a partir de dicionários e gramáticas, mas de enunciações concretas que nós mesmos ouvimos e reproduzimos na comunicação discursiva viva com as pessoas que nos rodeiam. Assimilamos as propriedades da língua somente nas formas das enunciações e justamente com essas formas. As formas da língua e as formas típicas dos enunciados, isto é os gêneros do discurso, chegam à nossa experiência e à nossa consciência em conjunto e estreitamente vinculados. Aprender a falar significa aprender a construir enunciados, porque falamos por enunciados e não por orações isoladas e, evidentemente, não por palavras isoladas. (BAKHTIN 1992, p. 282-283)

Assim, as novas formas de ler e escrever como práticas de letramento advindas do ambiente digital possibilitam avanços na estrutura dialógica da comunicação, tão importante na formação de cidadãos para atuarem numa sociedade que envolve interações reais e virtuais com tecnologias da informação e da comunicação na variedade dos gêneros do discurso, podendo revelar aspectos da personalidade individual dos sujeitos que vivenciam essas experiências.

A partir desse pressuposto, a escola precisa ver os gêneros textuais digitais como possibilidades de potencializar o estudo da língua, evidenciando práticas sociais linguísticas eficientes em significados e significantes pertinentes às compreensões reflexivas da leitura e da escrita na vida cotidiana. Contudo, muitos espaços educacionais ainda apresentam uma incompatibilidade estrutural na aceitação dos gêneros digitais como possibilidades do letramento alfabético.

Os gêneros textuais digitais são variados, temos e-mails, chats, listas de discussões, conversações em redes sociais, blogs, fóruns de discussões e outros. Todos eles exploram conteúdos que integram escrita, imagem, vídeos, sons em hipertextos e hiperdocumentos. Atualmente esses gêneros são bastante utilizados inclusive para formação inicial e continuada de educadores, pela facilidade comunicativa no ciberespaço.

Dessa forma, é irrefutável que a internet possibilita autoria, leitura e escrita, permitindo um aprimoramento da língua materna, corroborando o pensamento de Bakhtin (1992) quando afirma que a nossa construção vocabular e a estrutura gramatical não chegam ao nosso 
conhecimento a partir de dicionários e gramáticas, mas de enunciações concretas que nós mesmos ouvimos e reproduzimos na comunicação discursiva viva com as pessoas que nos rodeiam de formas variadas, inclusive em ambientes virtuais.

Essa interação dos sujeitos com tecnologias da informação e da comunicação potencializa práticas de letramento digital que contribuem diretamente na construção de linguagens no desenvolvimento de habilidades para a invenção do conhecimento no ciberespaço interagindo com os mais variados gêneros textuais alfabético e digital. Por isso, o professor tem um papel fundamental nesse contexto do desenvolvimento da linguagem como ferramenta de comunicação e interação social.

Nessa perspectiva, a escrita digital ganha uma grande funcionalidade à medida que alunos e educadores podem ser vistos como escritores e leitores, podendo refletir sobre o que escrevem, com a liberdade de escrever de forma mais abrangente e, portanto, com mais significado, sem limitar-se tão somente à escrita para avaliação escolar ou mesmo em processos seletivos.

Bakhtin (1992, p. 283) afirma que "a variedade dos gêneros do discurso pode revelar a variedade dos estratos e dos aspectos da personalidade individual". Urge, então, que a escola precisa ver os gêneros textuais digitais como possibilidades de potencializar o estudo da língua, evidenciando práticas sociais linguísticas eficientes como significados e significantes pertinentes às compreensões reflexivas da leitura e da escrita na vida cotidiana.

\section{ATUAÇÃO DOCENTE EM AMBIENTES VIRTUAIS DE APRENDIZAGEM}

O cenário educacional requer que o professor saiba utilizar os recursos pedagógicos tecnológicos para atuar no novo modelo de educação. Assim, é evidente a necessidade de assumir um perfil de pesquisador; formulador de proposta de trabalho; capaz de pôr em prática a teoria e teorizar a prática, buscando estar atualizado, aperfeiçoando-se para manter-se engajado com o sistema. Para ter todos esses requisitos, é indispensável que o docente planeje suas ações pedagógicas, além de participar das formações continuadas indispensáveis ao processo de desenvolvimento integral dos alunos.

Formar para as novas tecnologias é formar o julgamento, o senso-crítico, o
pensamento hipotético e dedutivo, as faculdades de observação e de pesquisa, a
imaginação, a capacidade de memorizar e classificar, a leitura e a análise de
textos e de imagens, a representação de redes, de procedimentos e de
estratégias de comunicação. (PERRENOUD, 2000, p. 182).

É necessário, portanto, que os professores busquem conhecimentos acerca de ambientes virtuais de aprendizagem seja através de cursos de formação continuada ou em parcerias com colegas que já tenham experiências bem sucedidas nesses espaços, e assim se apropriem de um letramento digital através de hipertextos e espaços de publicação e autoria, como blogs, enciclopédias e dicionários digitais, pois não é possível discorrer a respeito daquilo de que não se tem domínio.

O Letramento digital implica realizar práticas de leitura e escrita diferentes das formas tradicionais de letramento e alfabetização. Ser letrado digital pressupõe 
assumir mudanças nos modos de ler e escrever os códigos e sinais verbais e nãoverbais, como imagens e desenhos, se compararmos às formas de leitura e escrita feitas no livro, até porque o suporte sobre o qual estão os textos digitais é a tela, também digital. (XAVIER 2002, p. 2)

Compreendendo as novas práticas de atuação no ciberespaço, o professor terá condições necessárias de encaminhar os alunos a atividades de análise e reflexão de textos produzidos na rede de escrita digital, tendo, portanto, base teórica suficiente para a formação de leitores críticos, capazes de diferenciar os tipos de linguagens necessárias para atuar em cada espaço de aprendizagem, desenvolvendo, também, diferentes variedades linguísticas a fim de que a linguagem se adapte às mais diferentes realidades comunicativas.

$\mathrm{Na}$ tentativa de contribuir com professores de uma escola pública da rede estadual de ensino, organizou-se a partir de uma atividade prática de um curso de especialização, uma formação docente com oficinas pedagógicas envolvendo os gêneros textuais digitais e alfabéticos. Nesta experiência, utilizamos o laboratório de informática, internet e computadores para o desenvolvimento de atividades de pesquisa e construção de gêneros textuais com o propósito de potencializar a construção de novos conhecimentos e a proficiência leitora de estudantes do 3ㅇano do Ensino médio.

Para isso, houve a necessidade de uma articulação do sujeito com o objeto apreendido (conhecimento) em atividades que buscaram reflexão e análise em torno das vivências dos alunos, informações recebidas, orientações/mediações e as possibilidades de aplicação. Para todo esse processo, o discente utilizou representações verbais e não verbais (visuais e/ou auditivas, por exemplo).

Nessa perspectiva de construção, o professor deixa de ser visto como o detentor do conhecimento, o informador, mas o coordenador, o dinamizador no processo de ensinoaprendizagem, estimulando e acompanhando todas as etapas, proporcionando atividades de instigação, como pesquisas, debates, fóruns, gincanas, enquetes, pois, como afirma Paulo Freire (1990, p. 25): "Ensino não é a transferência do conhecimento, mas a criação das possibilidades para a sua produção ou para sua construção".

Nessa nova conjuntura de construção do conhecimento, o erro passa a ser visto também de forma construtiva, onde nada mais é que o princípio do acerto. Tal visão certamente afetará, de maneira positiva, a atuação dos alunos, a autonomia e até mesmo lhes possibilitará a elevação da autoestima, que deve acontecer não só através das possibilidades de educação colaborativa, de forma interativa, mas também com o amparo da teoria e da mediação docente.

O simples ato de escrever no editor de textos mostra como alguém pode registrar seu pensamento de forma distinta daquela do texto manuscrito, em que os erros são apagados sem marcas, sem constrangimentos, o fazer e o refazer são mais prazerosos, levando a novos processos de letramento. Contudo, o ensino de qualidade se definirá pela formação do profissional e por meio do planejamento adequado com o propósito de atuar e auxiliar na formação de alunos modernos, críticos, atuantes e reflexivos, que desejem aprender e utilizar espaços virtuais de aprendizagem para ampliar habilidades escritoras e leitoras, vislumbrando melhorias nas práticas discursivas sociais e pessoais. 
[...] a língua, oral e escrita, é fundamental para a participação social e efetiva, pois é por meio dela que o homem se comunica, tem acesso à informação, expressa e defende pontos de vista, partilha ou constrói visões de mundo, produz conhecimento. (BRASIL, 2001, p. 15)

Concordando com esses documentos que dão suporte teórico para elaborar projetos, propostas e ações educacionais, constata-se que a leitura e a escrita fazem parte das práticas sociais de comunicação. Em tempos remotos, a escrita era utilizada para contar os animais e acontecia através de marcas feitas em osso e madeira. Esses signos permitiam interpretações e registros que possibilitavam quantificar, identificar e negociar animais e objetos delimitados.

Atualmente, percebe-se que, com os avanços sociais e tecnológicos, a linguagem evoluiu junto, assim como seus significados e significantes; contudo, percebe-se, também, que ainda é alto o índice de escolas e professores que tratam a leitura e a escrita apenas como requisitos curriculares, práticas mecanizadas com regras gramaticais, desvinculando os valores linguísticos das experiências comunicativas sociais em seu entorno.

O diálogo é uma exigência existencial. $E$, se ele é o encontro em que se solidarizam o refletir e o agir de seus sujeitos endereçados ao mundo a ser transformado e humanizado, não pode reduzir-se a um ato de depositar ideias de um sujeito no outro, nem tampouco tornar-se simples troca de ideias a serem consumidas pelos permutantes (FREIRE, 1990, p.79).

Nessa conjuntura, observando o operar dos docentes nos espaços virtuais, nas redes sociais, percebe-se um movimento de autoria revestido por um caráter incentivador do diálogo, da comunicação e habilidades de leitura e escrita significativa. A internet ampliou a linguagem através de transcrições para uma escrita dialógica, comunicativa, com representações significativas e contextualizadas com as práticas sociais dos indivíduos envolvidos.

\section{METODOLOGIA}

Esta experiência trata-se de uma pesquisa intervenção em que organizamos um curso neste espaço, onde foram propostas diferentes experiências com gêneros textuais digitais, como: e-mails, chats, listas de discussões, conversações em redes sociais, blogs, fóruns de discussões e outros. Todos eles exploram conteúdos que integram escrita, imagem, vídeos, sons em hipertextos e hiperdocumentos. A metodologia utilizada foi qualitativa que envolveu entrevistas com os professores, oficinas pedagógicas em um curso de formação continuada.

Assim, para compreender na prática as possibilidades da inter-relação dos letramentos alfabético e digital no ciberespaço, organizamos em uma escola pública um curso de formação para professores do Ensino Médio envolvendo diversos gêneros textuais com atividades para serem desenvolvidas em sala de aula e no laboratório de informática.

\section{RESULTADOS E DISCUSSÕES}

Nesse estudo foram analisadas a participação dos professores, transcrições de escritas e construções relacionadas aos gêneros textuais para potencializar o letramento e a proficiência leitora de estudantes do 3o ano do Ensino Médio. 
Nestas análises foi possível constatar que a palavra sob o aspecto ideológico, as redes de escrita digital, podem proporcionar liberdade, quebrar velhas concepções e construir diferentes significados a partir de oportunidades de reflexão e construções de novas aprendizagens.

[...] A palavra acompanha todo ato ideológico. Os processos de compreensão de todos os fenômenos ideológicos (um quadro,uma peça musical, um ritual, um comportamento humano) não podem operar sem a participação do discurso interior. [...] Isso não significa, obviamente, que a palavra possa suplantar qualquer outro signo ideológico (BAKHTIN, 2006, p. 36-38).

Nos espaços virtuais, nas redes de escrita digital, o discurso dos professores assumiu um importante papel, pois não aconteceu de forma individual, mas entre interlocutores. A linguagem não foi falada no vazio, mas numa situação histórica concreta, partindo da interação de indivíduos, acontecendo uma inter-relação entre enunciação, condições de comunicação e as estruturas sociais de cada um, sendo o significado construído coletivamente.

Dessa forma, segundo os docentes participantes da experiência, a prática de leitura e escrita como pretexto apenas para o ensino gramatical impossibilita a construção de habilidades leitoras essenciais ao desenvolvimento da autonomia, reflexão e criticidade. Contudo, por meio de discussões, concluímos que as relações entre linguagem e sociedade devem acontecer de forma dialógica, considerando as experiências e oportunidades para que a linguagem aconteça de modo que transforme as práticas sociais, ampliando, assim, a construção de novas habilidades e conhecimentos indispensáveis para a representação do mundo, analisando os discursos que se apresentam de maneira clara e concisa.

\section{CONSIDERAÇÕES FINAIS}

A sociedade vem passando por grandes transformações que provocam mudanças em todas as suas esferas organizacionais, inclusive na área educacional. Assim, é preciso aprender a lidar com as informações, construindo habilidades para transformá-las em conhecimentos, facilitando as relações interpessoais em todos os âmbitos sociais, inclusive no educacional.

Os gêneros textuais, presentes no contexto da tecnologia digital, têm como finalidade comunicar, informar, formar, instruir, analisar e oferecer oportunidades de produção e autoria de forma dialógica e de interação em espaço virtual, como em chats, blogs, redes sociais e enciclopédias digitais, oportunizando a alunos e professores a interação com as Tecnologias da Informação e da Comunicação como instrumentos potencializadores da leitura e escrita, que possibilitam a inter-relação dos letramentos alfabético e digital nas práticas educativas e sociais.

A abordagem da leitura e escrita é um tema que merece reflexão diante das novas propostas que se apresentam na sociedade da informação, tendo em vista as diversas oportunidades de efetivação das várias alternativas de produção textual seja em espaço real ou virtual, haja vista que as aulas não devem mais acontecer de forma unilateral, tampouco focalizando convenções da nomenclatura gramatical, deixando de explorar, desse modo, todas as possibilidades que a língua como prática de interação discursiva propicia, bem como de desenvolver aptidões de leitura dos mais variados gêneros, fator preponderante à formação de leitores mais proficientes. 
Dessa forma, quanto mais o aluno tiver a oportunidade de desenvolver a acuidade leitora, maiores serão as possibilidades de confrontar ideias, analisar dados e sentidos para os diversos discursos existentes, além de serem capazes de construírem as suas próprias concepções e interpretações.

Nesta perspectivas, o presente estudo trouxe discussões, atividades práticas e reflexivas para uma busca de transformações que considerem a prática discursiva de estudantes e educadores uma experiência desencadeadora de processos cognitivo afetivos, possibilitando um acoplamento tecnológico em atos de escritura no ciberespaço, de forma que venha favorece a configuração de oportunidades de autoria e de potencialização da experiência do conhecimento, permitindo tomar nas mãos a construção do conhecimento na interação direta com as produções que surgem na interface da educação e tecnologia.

\section{REFERÊNCIAS BIBLIOGRÁFICAS}

1. BAKHTIN, M. Estética da criação verbal. Tradução Maria Ermantina Galvão PEREIRA. 4. ed. São Paulo: Martins Fontes, 1992; 2003;

2. __ VOLOCHÍNOV, V. N. Marxismo e filosofia da linguagem: problemas fundamentais do método sociológico na ciência da linguagem. Tradução Paulo Bezerra. 12 ed. São Paulo: Editora Hucitec, 2006.

3. BRASIL. Parâmetros curriculares nacionais: língua portuguesa. Brasília, 2001.

4. FREIRE, Paulo; MACEDO, Donaldo. Alfabetização: leitura do mundo, leitura da palavra. Rio de Janeiro: Paz e Terra, 1990.

5. LEVY, Pierre. Cibercultura. São Paulo: Unesp, 1999.

6. As tecnologias da inteligência S. Paulo: Editora 34, 1996.

7. 0 que é virtual. S. Paulo: Editora 34, 1996 b.

8. PERRENOUD, Philippe; RAMOS, Patrícia Chittoni. (Trad.). Dez novas competências para ensinar. Porto Alegre: Artes Médicas Sul, 2000.

9. XAVIER, Antonio C. S. O Hipertexto na sociedade da informação: a constituição do modo de enunciação digital. Tese de Doutorado, Unicamp: inédito, 2002. 